\title{
Study and application of the training system of disaster prevention and early warning of electric power
}

\author{
Liu Jianhua, Hong Tao, Xu Dongwei \\ Skill Training Center Liaoning Electric Power Supply Co.,Ltd., State Grid \\ 13940605903@126.com
}

Keywords: disaster prevention, training, early warning

\begin{abstract}
The extensive utilization of electric power makes the safety of power supply facilities become the priority among priorities, and the failure of the power supply facilities will bring immeasurable loss. How to prevent in advance, response rapidly to the failure, and recover rapidly power supply is the important responsibility of power supply companies and power repair departments. In order to improve the efficiency of emergency repair work, and the ability to deal with the power grid failure, it needs to solve such issues as setting repair command and reasonable scheduling repairmen, in addition to increasing manpower and materials of repair work. Besides, it needs to improve the professional quality and reduce injuries and deaths of maintenance personnel. If early warning plan can be formed in advance to deal with the emergencies, it will prevent and deal with the problems of facilities in a better way.
\end{abstract}

\section{The significance of the project}

With the rapid development of electric power construction, the reliability index of power quality increases, and "to improve the reliability of power supply, and ensure the safe operation of the power grid" is the fundamental requirement for the development of power grid. With the development of society and economy, the influence of meteorological disasters on power production becomes more and more obvious. Due to the broad area of overhead transmission line, most equipments of the transformer substation are exposed to nature in years, and once there are meteorological disasters such as, storm, lightning, ice and snow, the safe operation of the power system is facing enormous challenges, and trip circuit often occurs, which seriously impacts on the safety of power system production. In January 2008, the large scale of ravaged power grids caused by snow and ice disaster in Southern China resulted in the direct economic loss of 15.16 billion yuan. According to the statistical results of Electric Power Research Institute in 20 years, natural disasters have become the second main factors after the equipment failure, of the loss of stability of power network system. Therefore, with the development of society and economy, it is imperative to understand the characteristics of meteorological disasters in the region and analyze its influence on electric system. It is an urgent issue facing the power system on how to improve the disaster prevention and mitigation capacity. These issues are very important for effectively preventing and alleviating the losses caused by meteorological disasters and meaningful for preventing disasters and reducing damages.

This project fully integrates application information system, computer technology and communication technology and other high-techs, to do real-time monitoring and early warning assessment of the meteorological disasters and large area blackout accidents, which provides timely, accurate and reliable information for the trainees' reference in the training center, so that disaster prevention and reduction has a full scientific basis of early warning.

\section{General review of domestic and foreign researches}

Review of domestic researches: According to the investigation of the relevant departments, the construction of power disaster warning platforms have been developed in China, which are mainly in Fujian area, because of the frequent occurrence of typhoons, heavy rain, lightning and other natural disasters there. According to the characteristics of high fault rate of line, the power disaster 
prevention and early warning system is developed, which integrates the power plant, substation, transmission line, etc into the early warning system (GIS system). However, because of the big difference between north and south, the system which is mainly for the typhoon and rainstorm warning, has no introduction to the climate of the north, so that the system has not been used in the north.

Review of foreign researches: The foreign developed countries have set up coordinated and effective specialized agencies in the management of power disaster prevention and early warning, but due to the difference of their respective administrative management systems and legal systems, the settings of the organization and management system of power disaster prevention and early warning system are different either. The federal power disaster early warning of the United States was gradually towards unification from the beginning of 1990, but due to the regional and national differences, the construction of foreign power disaster early warning differs dramatically with that of China.

\section{The project's theoretical and the practical basis}

\section{Theoretical basis of the project}

(1) design process:

This system development is made up of two parts: one is building the related equipment, related work scene, and the production of tools and other models and management system of power disaster prevention and early warning platform, and the other is developing the relevant software. Specific procedures are as follows:

(2) production process of animation:

1) animation tools:

This paper chooses 3DMax, which is open and powerful, as a tool for making the animation. It has the characteristic of setting up the model, material settings, photo lighting, scene design, animation production and film editing, which lays a foundation for the production of high-quality animation works.

2) the location of the animation scene:

The main scene of the system includes the primary substation, the main control room, the working apparatus, storage batteries, $10 \mathrm{KV}$ high voltage power distribution room, low voltage AC room, 66KVLF6 high voltage power distribution room, and reactor room.

3) modeling:

The modeling process includes two aspects of scene modeling and equipment modeling. The scene modeling is the modeling aiming at the above standard scene and according to the background environment, including the main control room, the switch field, the door, the surrounding environment, etc.. Equipment modeling is the modeling aiming at the above substation and various equipment of the main control room. Equipment modeling is the key to the system. During the standard operation of electric power, the results of the operation are shown on the device too. So only when the equipment modeling is done meticulously, it meets the requirements of the performance of power operation, so the equipment modeling is based on fine models.

In the process of modeling, this paper will show the vivid and detailed equipment scene in three-dimensional drawings, which interpret the various details of the actual equipment from three perspectives. Through the application of this technology, the business object of vivid description of the equipment is realized.

4) animation motion design:

The advantage of animated performance is to use the dynamic images to present movements, which is the main embodiment of animation level. In order to describe every detail of the operation process completely in detail, this paper puts a lot of effort into the design of the animation.

In the power system, every step of the operation is limited by strict work rules and regulations, so in order to guarantee product quality, this paper completes the motion design in three steps.

First of all, power experts and designers present the motion process through simple sketching. 
Secondly, the hand sketching data are generated into the animation motion prototype without render through the 3DMax tool by designers. At this point, the model has been able to fully show the motion process.

Thirdly, the animation motion model is reviewed by power experts. If there is a problem, it will be modified. Finally, the prototype passed the review will be rendered, and the animation material is generated. Such strict requirements ensure that the animation motions are played strictly in accordance with the power system operation regulations and operation process.

The design requirement of non - standard operation animation is that it fully presents the non-standard operation procedure, and accurately restores the real situation of the scene.

5) final performance:

The final form of animation production refers to the fidelity of animation, color and movement performance so at to achieve the real and vivid teaching effect. Here this paper puts forward three technical indicators of smooth movement, vivid color, and special effects.

Smooth movement refers to the characters and equipment movements, in the movement process, follow the actual law of action, so the visual sense is natural and smooth.

Vivid color refers to the referring of the character models to achieve a vivid effect, so as to make the audience have the natural and delicate feeling and more easily indulge into the animation plot.

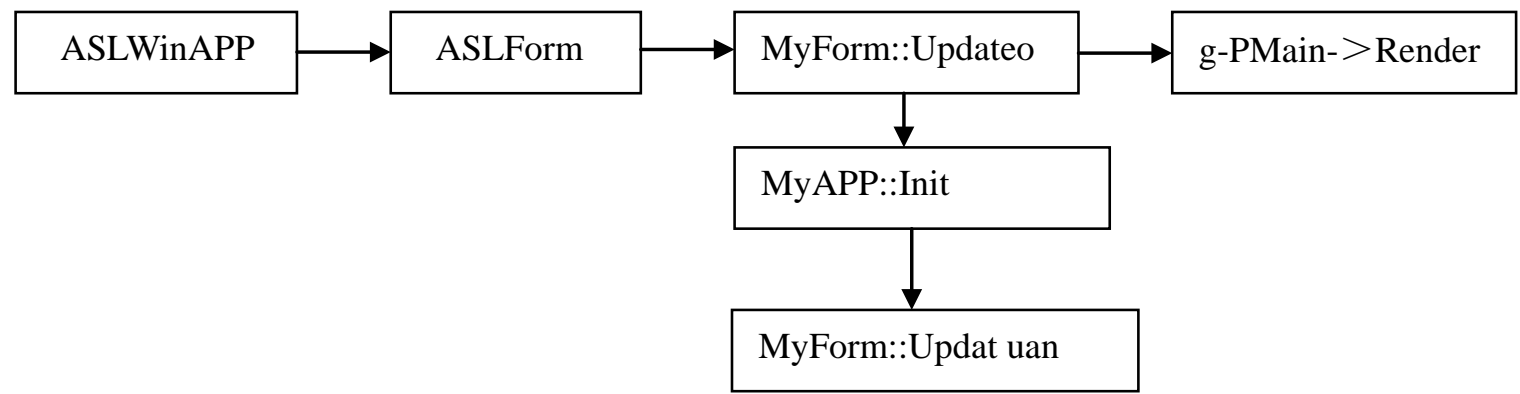

(3) software production process:

1) the main path

2) file format

The scene file and the 3D model file are all binary format (INI or XML).

Video file uses RMVB format

3) writing language

Using C language

4) loading speed

A, while source codes are programmed, the Lnit functions of MYForm shall be as simple as possible, so as to avoid the impact of loading speed.

$\mathrm{B}$, Avoiding the use of inappropriate data structure, so as to avoid the impact of the loading speed.

C, Using loop calling based on the need to avoid capacity increase of the database.

5) code test

A, Using automatic test framework to test the program code.

B, Doing batch test by Get Set.

$\mathrm{C}$, Clearing up the incorrect delete memory in accordance with the way of the files

$\mathrm{D}$, Checking all the functions of Load MeshLond.

\section{Project research content and implementation plan}

\section{1)Research content}

(1) By Web 3D virtual reality demonstration, the power scene is designed to simulate the actual electric power structure and display the actual scene from the horizontal and vertical direction.

(2) The project builds failure simulation scenes, including setting power scene, building power transmission line scene, rehearsal of the large scale of blackout of collapsed field lines, making scene of the important powering consumption units such as mines, schools and hospitals, as well as 
simulating scene by building a substation of $220 \mathrm{kV}$ and a substation of $66 \mathrm{kV}$. It focuses on the company's existing 1 overall plan, 8 special plans, to carry out the relevant software design route. The response scheme is planned in advance, to ensure the first time response to the failure. From the entire process of discovery, management, application, maintenance and continuous improvement of the hazardous points, the implementation of a rigorous security culture fundamentally improves the safety factor.

(3) According to the information of the 3D model and the GIS data, the real situation of the power construction is reproduced. All management objects are placed in a real three-dimensional world, which really achieves "what you see is what you get" in the management theories.

\section{2) Technical scheme}

Technical characteristics of power disaster prevention and warning system

Technical review:

The complete set of software adopts DirectX technology, which is an application interface (API) developed by Microsoft Corporation, and it is able to improve the implementation efficiency of multimedia applications on Windows platform, strengthen the 3D graphics and sound effects, and provide a common hardware driver standard for designers. It plays a key role in the development of multimedia applications on Windows platform.

\section{Conclusion}

Research on this project is expected to provide assistance for the professionals of power industry, enhance the professional competence of maintenance personnel, reduce their injuries and deaths and ensure the safe and reliable power generation.

\section{Referenc}

[1] The eighteen major anti accident measures of China State Grid Corpoaration [Z].

[2] Construction management [Z].

[3] The collection of provisions of the national power grid security management [Z].

[4] Tian Yuping. Questions and answers of anti-violation of power enterprises [M]. Beijing: China Electric Power Press, 2008

[5] Li Donglai, Zhu Jianjun. Rules and prevention of violation [J]. Chinese electric power enterprise management.2010.

[6] Huang Xianhua. Analysis of the application of anti-violation in electric power production safety management [J]. Chinese power education, 2009 